\section{(6) OPEN ACCESS}

\title{
An individualised, non-pharmacological treatment strategy associated with an improvement in neuropsychiatric symptoms in a man with dementia living at home
}

\author{
Mark McLean Carter, ${ }^{\oplus 1,2}$ Angelina Wei, ${ }^{1}$ Xinlei Li ${ }^{1}$
}

'Dementia Services, Care Visions China, Beijing, China ${ }^{2}$ Care Visions Dementia Care, Care Visions, Stirling, UK

Correspondence to Mark McLean Carter, mark.carter@carevisions.cn

Accepted 15 April 2019

Check for updates

(c) BMJ Publishing Group Limited 2019. Re-use permitted under CC BY-NC. No commercial re-use. See rights and permissions. Published by BMJ.

To cite: Carter MMcL, Wei A, Li X. BMJ Case Rep 2019:12:e229048 doi:10.1136/bcr-2018229048

\section{SUMMARY}

More than $90 \%$ of people with dementia experience neuropsychiatric symptoms which are often distressing and can result in early institutionalisation, diminished quality of life, increased frequency of emergency department visits along with stress and ill-health in caregivers. Non-pharmacological interventions are recommended as first-line treatment for neuropsychiatric symptoms, instead of medications such as atypical antipsychotics which have significant side effects. Most systematic reviews of non-pharmacological interventions for neuropsychiatric symptoms of dementia focus on patients in long-term care facilities and there are a limited number of research studies assessing the use of non-pharmacological interventions for patient's living at home. In this case report, we discuss an elderly man with dementia whose cognitive symptoms were accompanied by significant neuropsychiatric symptoms of suspicion, delusions, agitation and aggression. We describe how a programme of individualised, non-pharmacological interventions was associated with an improvement in neuropsychiatric symptoms within 3 months.

\section{BACKGROUND}

With the escalating global challenge of caring for 132 million people with dementia worldwide by $2050,{ }^{1}$ and no current pharmacological cure, there is a significant need for further research and innovative solutions for dementia care, ${ }^{2}$ especially for people who would prefer to remain in their own home. In addition to cognitive symptoms, the neuropsychiatric symptoms of dementia, also known as behavioural and psychological symptoms of dementia, occur in $>90 \%$ of people with dementia. ${ }^{3-6}$ These neuropsychiatric symptoms include agitation, aggression, apathy, depression, elation, disinhibition, anxiety, irritability, sleep disturbances, wandering, repetitive questioning, delusions, hallucinations and psychosis. ${ }^{3} 4$ 7-10 Neuropsychiatric symptoms are often distressing and can result in early institutionalisation, diminished quality of life, increased frequency of emergency department visits along with stress and ill-health in caregivers. ${ }^{3} 4-10$

Non-pharmacological interventions are recommended as first-line treatment for neuropsychiatric symptoms, instead of medications such as atypical antipsychotics which have significant associated side effects including stroke and death. ${ }^{11}$ While there have been several systematic reviews of the use of non-pharmacological interventions for the treatment of neuropsychiatric symptoms of dementia, 36-1012 most of the studies assessed focus on patients in long-term care facilities. There are a limited number of studies assessing the use of non-pharmacological treatment strategies for neuropsychiatric symptoms for patients living at home which focus on potential triggers of patient behaviours and behaviour modification strategies, ${ }^{13}$ interventions around environment and patient capabilities $^{14}$ and tailored activities delivered by occupational therapists and nurses. ${ }^{15}$ There is, however, a current and projected global shortage of healthcare professionals, ${ }^{16}$ and this is acutely felt in China where there is a shortage of doctors, nurses and occupational therapists. ${ }^{17-19}$ In China, there is also a lack of adequate medical school training in dementia care and as a consequence, a lack of doctors confident in the diagnosis and management of dementia. ${ }^{20} 21$ With an insufficient number of memory clinics in China to meet the growing prevalence of people with dementia, ${ }^{21}$ there are continued barriers to proper dementia diagnosis and management. The dementia service programmes discussed in this report are provided by trained staff members including a social worker and a care manager. The care is paid for privately by the individual or their family. There is no government funding provided for home-based or community-based dementia care programmes in China and currently dementia care is paid for out of pocket or by health insurance for those who are insured. ${ }^{20} 22$

In this case report, we describe how a programme of individualised, non-pharmacological interventions implemented for a man with mixed dementia living in his own home, was associated with improvement of his significant neuropsychiatric symptoms within 3 months.

\section{CASE PRESENTATION}

A man in his late 70s was living with his wife in a four bedroom apartment in urban Beijing, China. The patient presented with memory deficits including loss of short-term memory based around handling of his finances, not knowing who his 
children were and what they were doing for him, and not recognising his wife whom at times he would mistake for his mother. He was becoming disorientated daily to place and directions and had been getting lost in his own neighbourhood. These memory symptoms were accompanied by episodes of significant suspicion focused mainly on his finances and as a result of his concerns, he would become very agitated and at times verbally and physically aggressive. He was experiencing auditory hallucinations in which he thought he heard his family talking about his finances. He was having persecutory delusions and accusing his son-in-law of stealing his pension, as well as trying to murder him. He would often physically and verbally attack his eldest daughter for not protecting him and would become agitated towards his wife for not supporting him. He also stopped engaging with his friends and neighbours and had stopped musical and gardening activities which he previously enjoyed.

The patient had no previously diagnosed chronic conditions, medical or psychiatric history and no known cardiovascular risk factors. He was not taking any regular medications prior to his diagnosis of dementia. In 2014, he was diagnosed with a mixed form of dementia (Alzheimer's disease and vascular dementia), by his local physician who then prescribed donepezil, as well as Ginkgo Biloba and multivitamins. The patient was a non-smoker and drank no alcohol. He was formerly a teacher of chemistry and mathematics as well as a primary school principal. According to his family, he was of a very high intellect during his years of active teaching. He previously had hobbies such a listening to and playing music, and gardening.

The patient's eldest daughter visited his apartment three times a week to provide some care support and was the main spokesperson for the family. His younger daughter worked overseas. The family had employed a male care worker to stay and care for the patient full time. After 10 days, the male care assistant resigned because of the stress of caring for the patient. The patient would consistently wake up during the night causing carer fatigue. The care assistant's departure resulted in the need to employ a new care assistant. The patient's wife had to be moved into a separate one bedroom flat in the same building due to her own significant and increasing medical care needs and to minimise disruption of her care.

In early April 2018, the family contacted our dementia service team requesting help in dealing with the patient's worsening suspicion, agitation, aggression, disorientation and increased isolation. The family described that they felt a significant burden in caring for the patient and the related stress was having a negative impact on the patient's relationship with family members.

\section{INVESTIGATIONS}

At the time of diagnosis of mixed dementia in June 2014, there was no further formal cognitive screening, diagnostic imaging or pathology done to further confirm the diagnosis or stage of illness due to financial constraints and barriers to definitive dementia diagnosis in China. ${ }^{16-21}$ It should be noted that our dementia service organisation does not conduct the dementia diagnosis process. The local physician provided the presumptive diagnosis of mixed dementia to the patient and family. This diagnostic information was then provided to the care manager when the family applied to arrange the patient's in-home dementia programme.

From initiation of the programme in April 2018, the frequency of neuropsychiatric symptom episodes of suspicion, delusions, agitation and aggression were recorded as shown in table 2 in the Outcome and follow-up section.
The patient was also assessed and scored at the end of each month by the care manager using the following assessment tools with scores presented in table 3 in the Outcome and follow-up section.

- Mini-Mental State Examination. ${ }^{23}$

- Clinical Dementia Rating Scale. ${ }^{24}$

- Global Deterioration Scale/Functional Assessment Staging. ${ }^{25-27}$

- Geriatric Depression Scale. ${ }^{28}$

- Barthel Index of Activities of Daily Living. ${ }^{29}$

- Quality of Life in Alzheimer's Disease Scale (QoL-AD). ${ }^{30}$

\section{DIFFERENTIAL DIAGNOSIS}

The presumptive diagnosis of mixed dementia was made by a local physician. The presenting features of disorientation, confusion, poor judgement and behavioural changes are typical for Alzheimer's disease, while the presentation of impaired ability to make decisions and organise his finances earlier on in the course of his condition, could be suggestive of vascular dementia. ${ }^{31}$ However, it is notable that the patient had no previous history of cardiovascular risk factors or stroke. Personality and behavioural changes, including suspiciousness and agitation, may start to develop in the moderate stage of Alzheimer's disease, along with the cognitive symptoms of difficulty in doing usual daily tasks, confusion about where they are and wandering. ${ }^{31}$ In vascular dementia impaired judgement or impaired ability to make decisions, plan or organise are more common initial symptoms in the earlier stages. ${ }^{31}$ This patient's neuropsychiatric symptoms developed after his onset of memory deficits and he had no prior history of psychiatric conditions.

There are many differential diagnoses to consider in a patient presenting with features of dementia; however, the social worker and care manager in our dementia service team are provided with the dementia diagnosis based on the information from the local physician and the deliver a dementia in-home programme designed to address and monitor the patient's individual symptoms. The in-home dementia programme service is provided as an adjunct to the patient's ongoing clinical care provided by the physician.

\section{TREATMENT}

In April 2018, the dementia service team which included a social worker and a social care manager initiated a systematic, non-pharmacological approach to treatment, involving the family members and community at the onset of treatment. A plan was devised to identify strategies and therapeutic interventions to meet the patient's needs and reduce the family's stress and burden of care.

Following initial assessment, key treatment goals were established as follows:

1. Build a trustful relationship between the male patient and his care providers and family members.

2. Develop coping mechanisms and strategies for the suspicion, persecutory delusions and to reduce the aggressive behaviour towards his family members and carers.

3. Improve the patient's orientation to familiar surroundings and people.

4. Improve his socialisation and support system within the community.

5. Relieve carer stress and burden.

A care plan was implemented from Monday to Friday for an hour a day which included: 
1. Assessment of triggers behind the patient's delusions and suspicion, verbal and physical aggression.

2. Relevant non-pharmacological interventions, including daily reality orientation.

3. Provision of family education.

4. Rebuilding connections with ex-colleagues and neighbours.

Within the first few visits, the social worker was able to build a trusting relationship with the patient. She discovered that the patient's loss of short-term memory, lack of recognition of family members and impaired ability to manage his finances resulted in him becoming suspicious of what was happening to his money as he did not see any of the cash from his pension at home. He also became accusatory of his wife and daughter over ownership of his property. The intersection of memory loss and impaired ability resulted in perceived stress for the patient which triggered delusions, agitation and aggression. The social worker initiated a reality orientation approach by explaining to the patient that his pension was deposited monthly into the bank where there were safety measures in place to protect his money and that only he, with his identity card, could withdraw the money from the bank tellers. The social worker immediately involved the family in this approach to show him his automatic teller machine card and property ownership certificate regularly as a daily reminder of his financial security, and they would take him to the bank to be reassured by the bank officials if his concerns relapsed significantly. Further training was provided for the caregiver and the family on ways to manage the neuropsychiatric symptoms of dementia and the associated manifestations.
The patient also had episodes when he could not recognise himself in the mirror as soon as he stepped out of the bathroom and would then become verbally aggressive towards his wife. These episodes were reduced after the social worker and the family covered the mirror up with specific dated newspapers during the time he would be in the bathroom, thereby helping the patient to keep orientated to date. A reality orientation board was implemented with the patient to help him recognise his family members, especially his wife, as well as his home address and directions. The social worker showed the patient photos of different people and his wife from past to present and helped him to recognise his wife. The social worker periodically conducted group activities with the patient as well as his wife to help with their relationship and interactions. With the aim of helping reduce the patient's frequent disorientation, the patient was brought into the community with his family, as this helped show him the way back home to reinforce the patient's memory of the home address and directions.

The social worker and caregivers also explored better ways to communicate and care for the patient. Talking therapy was applied to help rebuild family relationships with the patient. Reminiscence therapy, a reality orientation board and cognitive training were implemented with the aim of helping to strengthen the patient's memory and cognition. Music therapy and gardening therapy were intended to help reduce changes in mood, encourage positive engagement and help restore his former hobbies. A list of all the non-pharmacological interventions applied is presented in table 1 .

Table 1 Non-pharmacological interventions delivered to the patient between April and end November 2018

\begin{tabular}{|c|c|c|c|}
\hline $\begin{array}{l}\text { Non-pharmacological } \\
\text { interventions }\end{array}$ & Brief description of the intervention applied & Month commenced & No of sessions \\
\hline Talking therapy & $\begin{array}{l}\text { Participating in talking therapy is used to help people living with dementia through specific } \\
\text { difficulties such as anxiety, depression or personal growth. }{ }^{36}\end{array}$ & April 2018 & 13 \\
\hline Reality orientation & $\begin{array}{l}\text { Reality orientation aims to help people with Alzheimer's disease to increase their residual } \\
\text { cognitive abilities and maintain social interaction using neurosensory stimulation. The main } \\
\text { goal is to reorient people to their current place, date and time. }{ }^{123738}\end{array}$ & April 2018 & 20 \\
\hline Cognitive training & $\begin{array}{l}\text { Cognitive training, also known as cognitive stimulation therapy, uses a structured approach } \\
\text { to stimulate and engage with the aim of enhancing residual cognitive abilities and } \\
\text { functional skills, preserving implicit memory and uses visual imagery, word association and } \\
\text { categorisation tasks as the main treatment. }{ }^{1239} \\
\text { In this case, puzzle and problem solving, cognitive challenges (with books, pictures, numeric } \\
\text { exercises), short-term memory exercises and digital cognitive games were used. }\end{array}$ & April 2018 & 63 \\
\hline Reminiscence therapy & $\begin{array}{l}\text { Reminiscence therapy uses a life review procedure to allow the person with Alzheimer's } \\
\text { disease to actively search for memories from their own life and rebuild their life story, which } \\
\text { usually involves construction of a life workbook with personal materials such as photographs, } \\
\text { music and pictures, which then provides a memory aid. }{ }^{12} \\
\text { In this case, sessions included use of photos, pictures, music, video, traditional and cultural } \\
\text { games, game tools, a memory box and a memory book. }\end{array}$ & May 2018 & 14 \\
\hline Garden therapy & Garden therapy included planting, potting and maintenance of the garden. ${ }^{10}$ & May 2018 & 4 \\
\hline Music therapy & $\begin{array}{l}\text { Music therapy usually includes listening to songs or music passively or participating with } \\
\text { singing or musical instruments. }{ }^{6101240} \text { This patient sang songs at each session. }\end{array}$ & May 2018 & 18 \\
\hline Art therapy & $\begin{array}{l}\text { Art therapy includes visual arts such as painting, colouring, sculpting or viewing art works. }{ }^{40} \\
\text { The patient participated in painting, drawing, personalised artwork and handcrafts. }\end{array}$ & May 2018 & 7 \\
\hline Validation therapy & $\begin{array}{l}\text { Validation therapy is a method intended to validate the perceived reality and emotional } \\
\text { experience of an individual. }{ }^{637} \text { In this case, the social worker would provide agreement, } \\
\text { support, encouragement, empathy, praise and comfort. }\end{array}$ & June 2018 & 6 \\
\hline Smell therapy & $\begin{array}{l}\text { Smell therapy, commonly referred to as aromatherapy, ignites the sense of smell through the } \\
\text { diffusion of aromatic oils such as lavender or lemon balm into the environment, or using a } \\
\text { skin cream, and has been shown to reduce symptoms of agitation. }{ }^{69}\end{array}$ & August 2018 & 2 \\
\hline \multirow[t]{2}{*}{ Sensory stimulation } & $\begin{array}{l}\text { Sensory stimulation involved the use of a sensory bag or board to stimulate the sense of } \\
\text { touch. }\end{array}$ & October 2018 & 1 \\
\hline & & Total & 148 \\
\hline
\end{tabular}


Table 2 Frequency of episodes of neuropsychiatric symptoms of dementia experienced by the patient

\begin{tabular}{|c|c|c|c|c|}
\hline \multirow[b]{2}{*}{ Month } & \multicolumn{4}{|c|}{ Episodes of neuropsychiatric symptoms of dementia } \\
\hline & Suspicion & Delusions & Agitation & Aggression \\
\hline April 2018 & $>3 /$ day & $>3 /$ day & $>3 /$ day & $>3 /$ day \\
\hline May 2018 & $>3 /$ day & $>3 /$ day & 2-3/day & 2-3/day \\
\hline June 2018 & 2-3/day & 2-3/day & $1 /$ day & 2-3/day \\
\hline July 2018 & 2-3/day & $1 /$ day & $1 /$ day & $1 /$ day \\
\hline August 2018 & $1 /$ day & $1 /$ day & 3/week & 3/week \\
\hline September 2018 & $1 /$ day & 4/week & 1/week & None \\
\hline October 2018 & $1 /$ day & 4/week & 1/week & None \\
\hline November 2018 & $1 /$ day & 4/week & 1/week & None \\
\hline
\end{tabular}

$1 /$ month=once a month; $3 /$ week=3 times per week; frequency, $>3 /$ day=more than 3 times a day; $2-3 /$ month $=2-3$ times a month; 3-6/week $=3-6$ times a week; $4 /$ week $=4$ times per week.

Aspects of the patient's socialisation were addressed in the following practical ways. The social worker and eldest daughter persuaded the patient to communicate with his ex-colleagues on a social media (WeChat) group chat on his phone. They also arranged for the patient to attend a party held by the patient's ex-colleagues. In addition, the care manager approached the local neighbourhood residential committee spokesperson and provided education on dementia to better understand patient's condition and requested them to visit the patient once a month.

Throughout the programme, the team members provided caregiver support and training during the sessions in the patient's home, such as sharing with care assistant how to deal with client's behaviour, improve communication between the family members and the patient and further educate the caregivers on the dementia.

\section{OUTCOME AND FOLLOW-UP}

By July 2018, 3 months after initiation of the programme, a significant reduction was noted in verbally and physically aggressive incidents as well as fewer episodes of suspicion and delusions as demonstrated in table 2. Since the end of August 2018, there have been no further episodes of verbal or physical aggression. The patient has a better understanding of his finances and how his daughter is helping him manage them. While his financial understanding and memory of his financial affairs is not always perfect, the recurring reality orientation strategies are able to be implemented by his family and carers as frequent reminders of how his financial affairs are managed and protected. Along with the observed improvements in neuropsychiatric symptoms, there was no deterioration in the patient's levels of dementia, depression, functionality and quality of life as displayed in the scores in table 3. It was noted that the while the Global Deterioration Scale/Functional Assessment Staging system scores of 5 showed moderately severe cognitive decline for cognition due to the significance of his memory loss and moderate functional impairment in that the patient occasionally needed help selecting clothing; however, in terms of physical ability to complete activities of daily living, the patient was able to physically dress and groom himself independently and had no other impairments on the Barthel parameters resulting in the Barthel index score of 100.

The QoL-AD was based on patient input with some caregiver input when required and we were surprised not to see the score improve despite the reduced frequency of the neuropsychiatric symptoms. A speculative reason for this could be based on the fact the quality of life assessment is primarily based on the person's
Table 3 Results of relevant dementia, depression and quality of life scales in the patient over 8 months

\begin{tabular}{lllllll}
\hline $\begin{array}{l}\text { Assessment } \\
\text { month }\end{array}$ & MMSE & CDR & GDS/FAST & $\begin{array}{l}\text { GDS } \\
\text { (depression) }\end{array}$ & Barthel & QoL-AD \\
\hline April 2018 & 14 & 2 & 5,5 & 5 & 100 & 31 \\
\hline May 2018 & 14 & 2 & 5,5 & 5 & 100 & 32 \\
June 2018 & 14 & 2 & 5,5 & 5 & 100 & 33 \\
\hline July 2018 & 14 & 2 & 5,5 & 5 & 100 & 33 \\
\hline August 2018 & 14 & 2 & 5,5 & 4 & 100 & 33 \\
\hline September 2018 & 14 & 2 & 5,5 & 5 & 100 & 31 \\
\hline October 2018 & 14 & 2 & 5,5 & 5 & 100 & 32 \\
\hline November 2018 & 14 & 2 & 5,5 & 5 & 100 & 33 \\
\hline
\end{tabular}

MMSE, Mini-Mental State Examination scored out of $30 .^{23}$

CDR, Clinical Dementia Rating scale ratings $0=$ normal; $0.5=$ very mild; $1=$ mild $2=$ moderate; $3=$ severe. $^{24}$

GDS/FAST, Global Deterioration Scale Staging levels $1=$ no cognitive decline; $2=$ very mild cognitive decline; $3=$ mild cognitive decline; $4=$ moderate cognitive decline; $5=$ moderately severe cognitive decline; $6=$ severe cognitive decline; $7=$ very severe cognitive decline; Functional Assessment Staging levels $1=$ normal adult; $2=$ normal older adult; $3=$ early $A D ; 4=$ mild $A D ; 5=$ moderate $A D ; 6=$ moderately severe $A D ; 7=$ severe $A D .^{25-27}$ Barthel Index of Activities of Daily Living Scale: out of $100{ }^{29}$

GDS (depression), Geriatric Depression Scale $0-5$ normal; more than 5 indicates depression. $^{28}$

QoL-AD, Quality of Life in Alzheimer's Disease scale with a maximum score of $52 .^{30}$

subjective opinion on their own intrinsic sense of well-being within physical health, mood, relationships, cognition, domestic life and tasks like financial management. It is possible that the patient's perception of his life situation had not changed as he continued to receive support in managing daily life and he may not have recognised improvement in his neuropsychiatric symptoms in relation to his quality of life. In considering this aspect, we have recognised that for future cases, use of both the selfrated QoL-AD and proxy-rated QoL-AD questionnaire versions may be more able to demonstrate improvement in quality of life when taking into account both patient and family perspectives equally; however, it is has been noted that self-rated and proxyrated questionnaires may not be inter-reliable for score levels. ${ }^{32}$

An increase in socialisation with neighbours and the community was also noted. The patient's relationships with family members have improved. His wife now comes down to have a meal with the patient every day and joins in with therapy sessions from time to time. The patient likes to chat with the neighbours and enjoyed attending a party held by ex-colleagues. So far, the second care assistant has been managing well for the last 3 months since his employment in August 2018. The family decided to stop the dementia service at the end of November 2018 because of the significant improvements in the patient's neuropsychiatric symptoms and level of overall improvement. The family's plan was to see what would happen thereafter under the family and care assistant's care. As part of our usual approach to care in this situation, our team advised the patient's family they would be available if the patient was to require the services in the programme again in the future.

\section{DISCUSSION}

There are international efforts to promote the use of non-pharmacological interventions as first-line treatment for neuropsychiatric symptoms of dementia, ${ }^{3} 933$ supported by a growing body of evidence for benefit. ${ }^{3}$ 6-10 12 However, most of the studies assessed focus on patients in long-term care facilities rather than community-based or home-based strategies. There have been some home-based intervention studies focused on potential triggers of patient behaviours and behaviour modification strategies, ${ }^{13}$ interventions around environment and patient 
abilities, ${ }^{14}$ and tailored activities, ${ }^{15}$ which were delivered in person and telephonically by occupational therapists and nurse practitioners. ${ }^{13-15}$ The studies were carried out over 16 weeks or 4 months of the applied intervention period during which there was a demonstrated reduction in the frequency of behavioural and psychological symptoms of dementia and associated caregiver distress. ${ }^{13-15}$ Models of care that focus on individualised approaches to promote self-determination have been shown to be beneficial in the treatment of neuropsychiatric symptoms of dementia. ${ }^{3}$ With regards to the patient in this case report, we observed the reduction in neuropsychiatric symptoms within 3 months of starting the programme, which would be in line with the expected time frame based on the noted studies. ${ }^{13-15}$ The dementia service programme and interventions provided to the patient in this case report differ in that they are all delivered in person and can be delivered in resource-poor settings by other allied healthcare professionals such as social workers and healthcare assistants who receive relevant training. The programme has a multicomponent, structured approach which includes initial person-centred assessment on needs, environment and potential behaviour triggers; education of the family, caregivers and community on dementia care and management; and a personalised, one-on-one programme of selected non-pharmacological intervention sessions. We acknowledge that the observation of associated improved neuropsychiatric symptoms of dementia in one patient without a control case does warrant speculation; however, these observations have prompted the initiation of further methodological research into this approach.

While clinically, there is a lack of available definitive testing and confirmation of dementia subtype in China, the programme of dementia services discussed in this case can be implemented for symptom-based management in resource-poor settings. This case demonstrates that using an individualised approach to implementing non-pharmacological interventions in the patient's own home can have a noticeable associated improvement in neuropsychiatric symptoms of dementia. In turn, there was a related perceived improvement in family dynamics and caregiver stress based on verbal reports from the family and care assistant. At the time of this programme was provided to this patient, the team did not have any instruments in place to specifically measure caregiver burden. However, there was a daily behaviour record maintained and the social worker included in the service notes feedback from the family members and care assistant on how the changes were affecting them. The environment and stressors in the patient's home had improved to such an extent that the wife who had previously had to move upstairs to a different flat due to the challenges posed by his neuropsychiatric symptoms, was able to move back downstairs to be with her husband again. However, it was a valuable lesson to learn at the time that we should monitor the caregiver burden both qualitatively and quantitatively. Subsequent to this case, our programmes now include instruments to measure caregiver stress and burden and additional tools to monitor behavioural and psychological symptoms of dementia.

With the anticipated increased burden of dementia on healthcare facilities and long-term care, ${ }^{34}{ }^{35}$ there is a crucial need for further trials and guidance on the effective implementation of non-pharmacological interventions, particularly in the patient's own home. We recognise the need for further such research and future trials to document the efficacy of non-pharmacological interventions for dementia such as the programme presented in the context of this case. As the work worldwide in the context of this structured approach to non-pharmacological dementia care is in developmental stages, and no trials are yet available, the observation and monitoring of outcomes on a case by case basis could provide a useful stepping stone to further development and rigorous trials in non-pharmacological dementia interventions.

\section{Learning points}

A non-pharmacological intervention programme for symptoms of dementia implemented in the patient's own home can help improve neuropsychiatric symptoms.

- Education of family members and caregivers on dementia and practical, simple ways to implement daily reality orientation can help manage neuropsychiatric symptoms of dementia.

- Monitoring dementia programme outcomes should include parameters for both the patient and the caregivers in order to qualitatively and quantitatively measure behavioural and psychological symptoms of dementia, quality of life and caregiver burden and stress.

Acknowledgements The authors would like to thank Charles Young and Zara Quail for their editorial oversight and input.

Contributors Conception and design, acquisition of data: MMC, AW and XL. Analysis and interpretation of data: MMC and AW. Drafting the article or revising it critically for important intellectual content: MMC. Final approval of the version published: MMC, AW and XL. Agreement to be accountable for the article and to ensure that all questions regarding the accuracy or integrity of the article are investigated and resolved: MMC.

Funding The authors have not declared a specific grant for this research from any funding agency in the public, commercial or not-for-profit sectors.

Competing interests Mark McLean Carter, Angelina Wei and Xinlei Li are employees of Care Visions China, the company providing the non-pharmacological dementia programme.

Patient consent for publication Next of kin consent obtained.

Provenance and peer review Not commissioned; externally peer reviewed.

Open access This is an open access article distributed in accordance with the Creative Commons Attribution Non Commercial (CC BY-NC 4.0) license, which permits others to distribute, remix, adapt, build upon this work non-commercially, and license their derivative works on different terms, provided the original work is properly cited and the use is non-commercial. See: http://creativecommons.org/ licenses/by-nc/4.0/

\section{REFERENCES}

1 World Health Organization. Global action plan on the public health response to dementia 2017-2025. 2017 http://www.who.int/mental_health/neurology/dementia/ action_plan_2017_2025/en/ (Accessed 3 Apr 2019).

2 Patterson C. Alzheimer's Disease International. The World Alzheimer Report 2018, The state of the art of dementia research: New frontiers. 2018 https://www.alz.co.uk/ research/world-report-2018 (Accessed 3 Apr 2019).

3 Caspar S, Davis ED, Douziech A, et al. Nonpharmacological Management of Behavioral and Psychological Symptoms of Dementia: What Works, in What Circumstances, and Why? Innovation in Aging. 2018;2:igy001-igy.

4 Steinberg M, Corcoran C, Tschanz JT, et al. Risk factors for neuropsychiatric symptoms in dementia: the Cache County Study. Int J Geriatr Psychiatry 2006;21:824-30.

5 Robert PH, Verhey FR, Byrne EJ, et al. Grouping for behavioral and psychological symptoms in dementia: clinical and biological aspects. Consensus paper of the European Alzheimer disease consortium. Eur Psychiatry 2005;20:490-6.

6 Scales K, Zimmerman S, Miller SJ. Evidence-based nonpharmacological practices to address behavioral and psychological symptoms of dementia. Gerontologist 2018;58(suppl_1):S88-S102.

7 Amieva H, Robert PH, Grandoulier AS, et al. Group and individual cognitive therapies in Alzheimer's disease: the ETNA3 randomized trial. Int Psychogeriatr 2016:28:707-17

8 Barton C, Ketelle R, Merrilees J, et al. Non-pharmacological management of behavioral symptoms in frontotemporal and other dementias. Curr Neurol Neurosci Rep 2016;16:14.

9 de Oliveira AM, Radanovic M, de Mello PC, et al. Nonpharmacological interventions to reduce behavioral and psychological symptoms of dementia: a systematic review. Biomed Res Int 2015;2015:1-9. 
10 Abraha I, Rimland JM, Trotta FM, et al. Systematic review of systematic reviews of non-pharmacological interventions to treat behavioural disturbances in older patients with dementia. The SENATOR-OnTop series. BMJ Open 2017;7:e012759.

11 Ballard CG, Gauthier S, Cummings JL, et al. Management of agitation and aggression associated with Alzheimer disease. Nat Rev Neurol 2009;5:245-55.

12 Cammisuli DM, Danti S, Bosinelli F, et al. Non-pharmacological interventions for people with Alzheimer's Disease: A critical review of the scientific literature from the last ten years. Eur Geriatr Med 2016;7:57-64.

13 Gitlin LN, Winter L, Dennis MP, et al. Targeting and managing behavioral symptoms in individuals with dementia: a randomized trial of a nonpharmacological intervention. $J$ Am Geriatr Soc 2010;58:1465-74.

14 Gitlin LN, Winter L, Dennis MP, et al. A biobehavioral home-based intervention and the well-being of patients with dementia and their caregivers: the COPE randomized trial. JAMA 2010;304:983-91.

15 Gitlin LN, Winter L, Burke J, et al. Tailored activities to manage neuropsychiatric behaviors in persons with dementia and reduce caregiver burden: a randomized pilot study. Am J Geriatr Psychiatry 2008;16:229-39.

16 Liu JX, Goryakin Y, Maeda A, et al. Global health workforce labor market projections for 2030. Hum Resour Health 2017:15:11.

17. Wu Q, Zhao L, Ye XC. Shortage of healthcare professionals in China. BMJ 2016;354:i4860

18 Zhou M, Zhao L, Kong N, et al. What caused seriously shortage of chinese nurses? Iran J Public Health 2018;47:1065-7.

19 Shi Y, Howe TH. A survey of occupational therapy practice in Beijing, China. Occup Ther Int 2016;23:186-95.

20 Chen Z, Yang X, Song Y, et al. Challenges of dementia care in China. Geriatrics 2017;2:7.

21 Jia J, Zuo X, Jia X-F, et al. Diagnosis and treatment of dementia in neurology outpatient departments of general hospitals in China. Alzheimer's \& Dementia 2016;12:446-53.

22 Gallagher-Thompson D, Tzuang Y, Au A, et al. Families dealing with dementia: insights from China, Hong Kong, and Taiwan. In: Karen E, Shripad T, eds. In aging Asia: the economic and social implications of rapid demographic change in China, Japan, and South Korea. Stanford, CA, USA: The Walter H. Shorenstein Asia-Pacific Research Center, 2010.

23 Folstein MF, Folstein SE, McHugh PR. "Mini-mental state". A practical method for grading the cognitive state of patients for the clinician. J Psychiatr Res 1975;12:189-98.

24 Morris JC. The Clinical Dementia Rating (CDR): current version and scoring rules. Neurology 1993;43:2412-4.
25 Reisberg B, Ferris SH, de Leon MJ, et al. The global deterioration scale for assessment of primary degenerative dementia. Am J Psychiatry 1982;139:1136-9.

26 Auer S, Reisberg B. The GDS/FAST staging system. Int Psychogeriatr 1997;9(Suppl 1):167-71.

27 Reisberg B, Jamil IA, Khan S, et al. Staging dementia. In: Abou-Saleh MT, Katona C, Kumar A, eds. Principles and practice of geriatric psychiatry. 3rd edn: John Wiley \& Sons Ltd, 2011:162-9.

28 Yesavage JA. Geriatric depression scale. Psychopharmacol Bull 1988;24:709-11.

29 Wade DT, Collin C. The Barthel ADL Index: a standard measure of physical disability? Int Disabil Stud 1988;10:64-7.

30 Logsdon RG, Gibbons LE, McCurry SM, et al. Quality of life in Alzheimer's disease: Patient and caregiver reports. J Ment Health Aging 1999;5:21-32.

31 Alzheimer's Association. Alzheimer's disease facts and figures. Alzheimers Dement 2018;14:367-429.

32 Römhild J, Fleischer S, Meyer G, et al. Inter-rater agreement of the Quality of LifeAlzheimer's Disease (QoL-AD) self-rating and proxy rating scale: secondary analysis of RightTimePlaceCare data. Health Qual Life Outcomes 2018;16:131.

33 Kales HC, Lyketsos CG, Miller EM, et al. Management of behavioral and psychological symptoms in people with Alzheimer's disease: an international Delphi consensus. Int Psychogeriatr 2018;2:1-8.

34 Keogh-Brown MR, Jensen HT, Arrighi HM, et al. The impact of alzheimer's disease on the Chinese economy. EBioMedicine 2016;4:184-90.

35 Prince MJ, Wimo A, Guerchet MM, et al. World alzheimer report 2015 - the global impact of dementia: an analysis of prevalence, incidence, cost and trends. London: Alzheimer's Disease International, 2015. https://www.alz.co.uk/research/world-report2015. (Accessed 3 Apr 2019).

36 Alzheimer's Society. Talking therapies (including counselling, psychotherapy and (BT). 2015 https://www.alzheimers.org.uk/sites/default/files/pdf/talking_ therapies_including_counselling_psychotherapy_and_cbt.pdf (Accessed 3 Apr 2019).

37 Mitchell G, Agnelli J. Non-pharmacological approaches to alleviate distress in dementia care. Nurs Stand 2015;30:38-44.

38 Camargo $\mathrm{CH}$, Justus FF, Retzlaff $\mathrm{G}$. The effectiveness of reality orientation in the treatment of Alzheimer's disease. Am J Alzheimers Dis Other Demen 2015;30:527-32.

39 McClam TD, Marano CM, Rosenberg PB, et al. Interventions for neuropsychiatric symptoms in neurocognitive impairment due to alzheimer's disease: a review of the literature. Harv Rev Psychiatry 2015;23:377-93.

40 Cowl AL, Gaugler JE. Efficacy of creative arts therapy in treatment of Alzheimer's disease and dementia: a systematic literature review. Act Adapt Aging 2014;38:281-330.

Copyright 2019 BMJ Publishing Group. All rights reserved. For permission to reuse any of this content visit

https://www.bmj.com/company/products-services/rights-and-licensing/permissions/

BMJ Case Report Fellows may re-use this article for personal use and teaching without any further permission.

Become a Fellow of BMJ Case Reports today and you can:

- Submit as many cases as you like

- Enjoy fast sympathetic peer review and rapid publication of accepted articles

- Access all the published articles

- Re-use any of the published material for personal use and teaching without further permission

For information on Institutional Fellowships contact consortiasales@bmjgroup.com

Visit casereports.bmi.com for more articles like this and to become a Fellow 